\title{
A PRECARIEDADE DO CONTEÚDO INFORMACIONAL DOS ANEXOS DE RISCOS FISCAIS DE MUNICIPIOS BRASILEIROS
}

\author{
Ricardo Rocha de Azevedo' \\ André Carlos Busanelli de Aquino² \\ André Feliciano Lino ${ }^{3}$ \\ Gabriel Cavalmoretti ${ }^{4}$
}

\begin{abstract}
Resumo: A pesquisa analisou o conteúdo informacional do relatório chamado de 'Anexo de Riscos Fiscais' emitido por governos locais, enviado com a Lei de Diretrizes Orçamentárias às Câmaras Municipais para o debate orçamentário. A elaboração do relatório está no centro do debate sobre sustentabilidade fiscal de governos. Foram comparados os relatórios emitidos por 12 prefeituras municipais no período de 2011 a 2016. Selecionamos aleatoriamente 9 municípios (na faixa populacional entre 100 e 200 mil habitantes) dos estados de São Paulo, Rio de Janeiro e Minas Gerais, além das respectivas capitais. As evidências para os casos analisados indicam que, em geral, os indicadores de risco e as providências associadas são genéricos e não atualizados, e, portanto, com baixo conteúdo informacional. Os resultados apontam que a fiscalização superficial dos Tribunais de Contas na questão pode gerar incentivos para prefeituras apresentarem estes anexos de forma cerimonial, com o único objetivo de cumprir a legislação fiscal. Tanto as prefeituras de menor porte analisadas, quanto as capitais dos estados apresentam sinais de uma gestão de riscos inexistente. A apresentação cerimonial desses indicadores e providências pode indicar a provável inoperância na gestão de riscos nos casos analisados, e, portanto, uma baixa capacidade de antecipação de crises ou choques.
\end{abstract}

Palavras-chave: Riscos Fiscais; Lei de Responsabilidade Fiscal; Lei de Diretrizes Orçamentárias; Sustentabilidade fiscal.

\footnotetext{
ricardo.azevedo@ufu.br - Universidade Federal de Uberlândia - http://orcid.org/0000-0001-6302-0760

2aaquino@usp.br - Universidade de São Paulo - http://orcid.org/0000-0002-0329-410X

3 aflino@ufpa.br - Universidade Federal do Pará - http://orcid.org/0000-0003-1121-4971

${ }^{4}$ gabriel182@icloud.com - Universidade de São Paulo - https://orcid.org/0000-0001-9063-3706

-DOI: http://dx.doi.org/10.14392/asaa.2019120201

- Artigo apresentado no VII Congresso Nacional de Administração e Contabilidade - (AdCont 2016 - RJ) e no XVII Congresso USP de Contabilidade - International Conference

in Accounting.
}

- Artigo submetido em: 13/01/2018. Submetido a nova rodada em: 01/04/2019. Aceito em: 21/08/2019. 


\title{
THE WORTHLESS INFORMATION IN BRAZILIAN GO- VERNMENTAL FISCAL RISK REPORTS
}

\begin{abstract}
The research analyzed the informational content of the governmental fiscal risk reports, the named 'Fiscal Risk Appendix', elaborated by local governments in Brazil complementing the annual budget guidelines law to the legislative scrutiny. The risk report elaboration is central to the governmental fiscal sustainability. We compared governmental risk reports elaborated by 12 city halls between 2011 and 2016. We randomly selected 9 municipalities from the strata of 100 up to 200 thousand inhabitants in 3 Brazilian states, São Paulo, Rio de Janeiro e Minas Gerais, additionally we included the respective state capitals. Our evidence for the cases analyzed pointed out the risk indicators and the associated responses are generic and not evaluated, therefore presenting a low informational content. City halls have prominent incentives to ceremonially report just to comply with the fiscal regulation, due the superficial control from Courts of Accounts. The city halls from medium size municipalities but also those from capitals present features of an unconvincing risk management. The ceremonial report of such risk indicators and the associated responses may indicate a probable inoperative risk management in the observed cases, and therefore a weak anticipatory capacity to deal with shocks and crises.
\end{abstract}

Palavras-chave: Fiscal Risks; Fiscal Responsibility Act; Budget guidelines law; Fiscal Sustainability. 


\section{INTRODUÇÃO}

A gestão de riscos pode ser caracterizada como o monitoramento da probabilidade de ocorrência de um evento com o potencial de afetar o desempenho de uma organização (Hardy, 2010), e se aplica desde desastres naturais até eventos econômicos. O Fundo Monetário Internacional (FMI) considera a gestão de riscos fiscais como uma das ferramentas de boas práticas de transparência fiscal para governos (Ramkumar \& Shapiro, 2014) e um dos princípios básicos para boa governança (Woods, 2009). Os impactos desse mecanismo de controle vão desde a redução de eventuais prejuízos causados ao potencial crescimento futuro, redução da probabilidade de déficits, até o impedimento da falência de serviços básicos (Brixi \& Schick, 2002; Hameed, 2005). Além disso, a gestão de riscos fiscais também ajuda a tornar os governos mais resilientes quando enfrentam choques inesperados (Kumar \& Ter-Minassian, 2007). Ao transparecer seus riscos fiscais, e como lidam com eles, os governos reduzem a incerteza sobre as contas públicas e melhoram a avaliação de seus ratings de crédito.

No Brasil, como parte do receituário internacional de ajustes fiscais que foi capitaneado pelo Banco Mundial na década de 90 (Alam \& Sundberg, 2002), a gestão de riscos fiscais foi introduzida pela Lei de Responsabilidade Fiscal (LRF) no ano 2000 (Ter-Minassian, 2010). Desde então, a gestão de riscos se materializa através do relatório chamado de Anexo de Riscos Fiscais (ARF), que deve acompanhar anualmente a Lei de Diretrizes Orçamentárias (LDO) dos governos. “Conforme a Secretaria do Tesouro Nacional (2017), o ARF demonstra os riscos fiscais (eventos prováveis que podem impactar negativamente as contas públicas) e suas providências (atos necessários para sanar o evento que ocorreu)."

Porém, não basta que haja uma previsão legal para que o controle seja efetivo. Quase duas décadas após a LRF instituir a gestão de riscos como ação compulsória para governos, uma análise de 2017 feita pelo FMI em âmbito federal apontou deficiências na divulgação dos riscos, apesar do Brasil ter sido um dos pioneiros na regulação da questão (Clements et al., 2017). O relatório do FMI sugere que o conteúdo informacional dos diversos riscos fiscais publicados pelo governo federal é baixo. Por exemplo, o relatório diz que "a documentação do orçamento discute e quantifica vários riscos específicos, mas não é abrangente e o vínculo entre os riscos e as previsões costuma ser pouco claro", além de diversas outras informações sobre riscos que não são sequer divulgadas (Clements et al., 2017:75).

Tais deficiências aconteceriam porque o movimento generalizado de adoção de regras de controle e monitoramento dos riscos fiscais estaria sujeito às mesmas limitações no processo de institucionalização de quaisquer outras práticas incluídas compulsoriamente via alteração legal. Tais limitações podem levar a uma implantação que objetiva apenas legitimação, gerando uso cerimonial e de baixa efetividade (Greenwood et al., 2008; Boxenbaum \& Jonsson, 2008). Como o ARF é um relatório de divulgação compulsória, a tendência é que ele seja produzido e enviado junto com o projeto de lei da LDO visando o cumprimento da lei. Dessa forma, o conteúdo informacional e uso dos relatórios sobre gestão fiscal tenderia a ser baixo.

Quanto aos governos locais, discute-se que estes têm dificuldade de antecipar choques e crises (Barbera et al., 2017), incluindo estudos nacionais, que discutem que estes não anteciparam a última crise econômica de 2014, como Aquino e Cardoso (2017). Parte dessa limitação na antecipação vem da inoperância dos instrumentos e técnicas de gestão de risco (Hameed, 2005; Kumar \&Ter-Minassian, 2007).

Neste contexto, a presente pesquisa discute o que explicaria o conteúdo informacional dos relatórios de riscos fiscais de municípios brasileiros, e como eles variam ao longo do tempo? 
Selecionamos aleatoriamente 9 municípios no estrato de 100 e 200 mil habitantes de três estados, Minas Gerais, Rio de Janeiro e São Paulo. Incluímos adicionalmente as 3 capitais desses estados para comparação. Analisamos o período de 2011 a 2016, período coincidente com a crise econômica de 2014. Foi feita análise de conteúdo de indicadores e providências de 72 relatórios. Os resultados apontam que em geral o conteúdo informacional dos relatórios de riscos fiscais é baixo, e isso se mantém ao longo do tempo. Discutimos que os motivos prováveis para esse baixo conteúdo informacional são (i) a baixa atenção do controle externo (dos Tribunais de Contas e Legislativo) em relação a essa temática; e (ii) a vinculação do ARF à dinâmica do ciclo orçamentário anual, que já enfrenta descrédito e alta imprecisão (Rezende \& Cunha, 2013), e às funções e áreas que são os operadores do orçamento.

O artigo contribui tratando do tema de gestão de riscos fiscais em governos, ainda pouco explorado empiricamente no Brasil. Mais do que isso, oferece para a literatura de mudanças organizacionais no setor público uma evidência de adoção cerimonial de controle trazido de forma compulsória pela legislação. Por fim, dá evidências para a literatura de resiliência financeira de mecanismos que melhorariam a capacidade de antecipação de choques, implantados superficialmente. Com isso, faz um alerta aos índices de agências internacionais que captam apenas a existência da regulação, e não a efetiva adoção das práticas.

O texto a seguir apresenta os conceitos centrais para a análise e contexto sobre a regulação brasileira para a informação de riscos fiscais. Na sequência são apresentados os dados e os métodos utilizados na pesquisa. Por fim, são apresentados resultados da análise e são feitas as considerações finais.

\section{A ADOÇÃO DE GESTÃO DE RISCOS FISCAIS E ANTECIPAÇÃO DE CHOQUES}

A capacidade de antecipação de tensões, como os riscos fiscais, é valorizada na literatura de resiliência financeira (Barbera et al., 2017). Antecipar tensões (ou crises) daria à organização uma chance de evitar os impactos indesejáveis do evento provável. Até mesmo por isso, desde o final dos anos 90 , a gestão dos riscos fiscais faz parte do toolkit a ser utilizado por governos para o planejamento público em diversos países (FMI, 2007; Hardy, 2010; HM Treasury, 2004; Freitas, 2016). Gerir riscos fiscais, em resumo, é evitar que ocorram desvios nas variáveis fiscais em relação ao que se esperava no momento da preparação do orçamento (Cebotari et al., 2008). Estes desvios, ou riscos identificáveis, podem ser classificados como temporários (risco de excesso de despesas no período anterior a uma eleição) ou permanentes (riscos da natureza) (Kopits, 2014).

No setor público brasileiro, a gestão de riscos fiscais foi introduzida pela LRF em 2000, inspirada na lei da Nova Zelândia, de 1994 (Fiscal Responsibility Act) e do guia de transparência fiscal do FMI (Nascimento \& Debus, 2001). A LRF demanda que o monitoramento dos riscos fiscais fosse realizado e publicado no relatório Anexo de Riscos Fiscais (ARF), que acompanha o projeto da Lei de Diretrizes Orçamentárias (LDO) enviado para aprovação pelo Poder Legislativo. O objetivo do relatório é"aumentar a transparência dar maior transparência às metas de resultado estabelecidas", permitindo (i) a identificação do tipo de risco e exposição ao risco, estruturando (ii) a mensuração ou quantificação dessa exposição e, incentivando (iii) a decisão estratégica sobre as opções para enfrentar o risco (STN, 2014: 38 ). O anexo deve apresentar ao Legislativo e à sociedade (i) os riscos previstos para o orçamento do exercício seguinte, $\mathrm{e}$ as (ii) providências a serem tomadas caso os eventos dos riscos elencados se concretizem (LRF, art. 4o, § 30). Tal relatório deveria instrumentalizar o Poder Legislativo com informações sobre os riscos fiscais permanentes e temporários e seus prováveis impactos nas contas públicas na execução do orçamento do exercício seguinte (STN, 2014). 
Contudo, poucos estudos trazem evidências empíricas sobre o desenvolvimento e uso dos dados de gestão de riscos fiscais no contexto do Brasil. As exceções sugerem que a adoção do ARF é uma resposta à exigência legal, porém, sem real utilidade para os governos. Por exemplo, Almeida-Santos (2015) mostra que solvência (endividamento e disponibilidade de caixa) não está associada à divulgação de riscos; Ferrari e Senhoras (2013) apontam para uma baixa sistematização da gestão de riscos no Governo do Estado de Santa Catarina, e Lopes e Costa (2017) discutem a divulgação do ARF por municípios que declararam estado de calamidade em 2015, mostrando que em 73 casos analisados de governos que publicamente reconheceram o impacto significativo de um choque, entre eles apenas três haviam divulgado riscos fiscais correspondentes.

A literatura institucional é extensa na explicação das prováveis razões pelas quais existem falhas na efetiva implementação do ARF em governos. Organizações, como as prefeituras, por vezes adotam novas práticas para obter maior legitimidade, e não objetivando a obtenção racional de ganhos de produtividade ou desempenho (Ashworth, Boyne \& Delbridge, 2007; Meyer \& Rowan, 1977). A legitimidade seria obtida junto aos principais atores do campo organizacional, formado por um agregado de organizações similares ou que estão conectadas em torno de uma mesma função social (DiMaggio \& Powell, 1983) como, por exemplo, o controle fiscal e orçamentário de governos. Governos locais, ou Prefeituras no Brasil, atuam em um campo organizacional que também conta com os Tribunais de Contas, Câmaras Municipais, Secretaria do Tesouro Nacional e Ministério Público. E, ao menos em parte, são esses atores que confeririam a legitimidade necessária para as Prefeituras no que se refere à desenvolvimento $e$ uso de informações sobre gestão de riscos. Assim, governos em municípios teriam motivações para se adequar às pressões institucionais que emergem da atuação dessas organizações do campo, que são tipicamente orientadas pela regulação fiscal e financeira, mas são sobretudo influenciadas pelas práticas profundamente enraizadas na administração pública nacional.

A demanda trazida pela LRF no que se refere à gestão de riscos é uma pressão institucional sobre os governos. As pressões institucionais são forças motrizes para mudanças organizacionais (como a adoção de novas práticas - no nosso caso, o ARF), e podem ser coercitivas, miméticas e normativas (Ashworth et al., 2007; DiMaggio \& Powell, 1983). Por um lado, tais pressões podem levar organizações a adotarem formas similares de estratégias, práticas, processos e estruturas, o chamado isomorfismo; por outro lado, essas podem responder de forma estratégica à estas pressões - o que possibilitaria que diferentes respostas fossem encontradas ao longo do campo organizacional (DiMaggio \& Powell, 1983; Oliver, 1991).

Pressões isomórficas coercitivas são expectativas de punição ou perdas por não cumprir uma regulação de um ator com poder. Mas organizações também sofrem pressão por mimetismo, quando preferem adotar soluções similares às utilizadas por outras organizações para reduzir incerteza de uma eventual escolha má sucedida. Por fim, pressões normativas estão associadas a valores e, em uma tentativa das organizações se legitimarem no campo organizacional, estas preferem se adequar às normas e padrões reconhecidos por profissionais da área (Ashworth, Boyne \& Delbridge, 2007; DiMaggio \& Powell, 1983).

Dentro desse contexto, há uma forte pressão normativa no cenário brasileiro, haja visto que o modelo adotado é o definido pelo Manual de Demonstrativos Fiscais da Secretaria do Tesouro Nacional, que propõe o gerenciamento de quatro tipos de riscos (frustração de arrecadação, restituição de tributos, discrepância de projeções e outros riscos fiscais), além dos passivos contingentes que também atuam como riscos (demandas judiciais, dívidas em reconhecimento, garantias concedidas) (STN, 2014).

Tais manuais operam como estruturas de orientação (templates), algo a ser seguido (benchmark) que legitimará quem adotá-lo, evitará apontamentos de não conformidade e atua reduzindo a incerteza de 
escolhas inovadoras. Como Oliver (1991) classifica, entre 5 típicas de respostas possíveis frente a pressões institucionais, em ambientes de forte pressão coercitiva e de resistência à mudança, é esperada como resposta estratégica a adoção cerimonial, com decorrente descolamento (decoupling).

Isso porque, quando as pressões externas aumentam, as organizações podem se legitimar através da adoção superficial das normas e processos (Scott, 2014), pois basta que "pareçam" que estão adotando para reduzir a pressão externa. Essa adoção superficial é chamada cerimonial ou um isomorfismo de superfície (Zucker, 1987). Este descolamento (decoupling) entre o que é divulgado pela organização e aquilo que está profundamente institucionalizado nas suas rotinas permite que as práticas utilizadas no dia-a-dia sejam preservadas mesmo quando existem pressões para a adoção de uma prática não aceita ou não valorizada, que passa a ser realizada superficialmente para ganho de legitimidade (Meyer \& Rowan, 1977).

Dessa forma, quando utilizados apenas para fins de ganhos de legitimidade, haveria uma maior propensão à dificuldade de antecipação dos choques relacionadas à inoperância dos instrumentos e técnicas de gestão de risco (Hameed, 2005; Kumar \& Ter-Minassian, 2007; Barbera et al., 2017).

\section{METODOLOGIA}

A lógica de análise do presente artigo se baseia no conteúdo informacional dos indicadores de riscos fiscais e providências de municípios. Consideramos que o conteúdo informacional de indicadores e providências é fator determinante para que o sistema de gestão de risco exerça apoio na antecipação de choques e crises, e seja um sistema operante. Como o relatório é o principal output do conjunto de processos e decisões que permeiam a gestão de riscos, consideramos que um relatório permeado por indicadores e providências sem conteúdo informacional ocorreria nos casos em que a gestão de riscos fiscais não é integrada à gestão municipal.

A análise típica de pequena amostra, compara casos entre eles (between cases) e a evolução deles no tempo (within cases) (Patton, 2015). Com isso busca a variação de padrões entre os casos, com amostragem "purposeful random sample" (Patton, 2015). Comparamos a fonte de coerção e normatização, eventuais fontes de influência normativa, mas mantendo a faixa populacional dos casos analisados. Selecionamos aletoriamente 3 municípios na faixa de 100 a 200 mil habitantes em 3 estados distintos, selecionados de forma proposital teoricamente orientado.

Optou-se por esta faixa, para propositadamente analisar casos em que não sofrem necessariamente da escassez grave de recursos dos municípios de pequeno porte, mas também não seriam casos extremos de grandes centros urbanos com mais fácil acesso à tecnologia e serviços especializados. Os municípios nesta faixa populacional são minoria no país. Nos 3 estados selecionados são apenas 67 municípios. Contudo, a análise nesta faixa mitiga os efeitos associados ao porte de municípios, mais proeminentes nos extremos.

Foi sorteada uma lista de municípios para cada estado, e partindo do primeiro da lista buscou-se os relatórios de riscos fiscais disponíveis nos portais de internet da prefeitura. Se não eram encontrados os relatórios, o próximo da lista sorteada foi incluído até completar os 3 casos por estado. A seleção e análise dos casos foi feita entre os meses de fevereiro a junho de 2016. Assim, os casos analisados são os municípios sorteados que possuíam relatórios divulgados.

A seleção dos 3 estados compara a fonte de coerção e normatização geradas pelos Tribunais de Contas, principal fonte externa de legitimação de normas fiscais para governos locais (Gustavson \& Rothstein, 2013). Tal força viria do mandato legal dado aos Tribunais de Contas para coerção da legislação 
fiscal, e da potencial orientação profissional e normativa. Contudo, a auditoria dos Tribunais de Contas varia quanto à intensidade e forma (Lino \& Aquino, 2018), além de terem diferentes interpretações da legislação fiscal (STN, 2013; Nunes et al., 2019). Foram incluídos três estados da mesma região do país, mas com Tribunais bem distintos em termos de contexto de sua operação. São Paulo e Minas gerais são representativos em jurisdicionados (644 e 853 respectivamente), mas diferem na forma como os riscos fiscais são acompanhados. OTribunal de Contas de São Paulo tem equipes de auditores descentralizadas em regionais, e o relatório é entregue em papel, cuja análise é feita de forma não automatizada. No caso de Minas Gerais, a entrega e análise é feita de forma eletrônica, com equipes de auditores centralizadas em Belo Horizonte. Por fim, a inclusão do estado do Rio de Janeiro traz interessante contraponto, dado o menor número de jurisdicionados (92), e recentes denúncias envolvendo seus conselheiros e alerta de maior inoperância do Tribunal. A Tabela 2 traz uma comparação dos Tribunais de Contas cujos estados foram selecionados.

Os 9 casos selecionados em comparação com os 67 municípios nesta faixa populacional têm leve inclinação para os mais populosos, mais distantes da capital, mais antigos, e de maior arrecadação comparados com os da mesma faixa no ano de 2015 (Tabela 1). Por fim, incluímos na amostra as 3 capitais desses estados para comparação por serem de maior parte, próximas do Tribunal de Contas e supostamente com maior acesso à tecnologia, equipes e serviços especializados. Analisamos o período de 2011 a 2016, período coincidente com a crise econômica de 2014, reunindo 72 relatórios anuais.

Tabela 1: Características gerais dos 9 municípios selecionados. Não inclui as capitais.

\begin{tabular}{|c|c|c|c|c|c|c|c|c|}
\hline \multirow{2}{*}{ Características dos municípios } & \multicolumn{3}{|c|}{$\begin{array}{c}\text { Casos selecionados para a análise } \\
\text { (exceto capitais) (n=9) }\end{array}$} & \multicolumn{4}{c|}{$\begin{array}{c}\text { Municípios entre } \\
100 \text { e 200 mil habitantes } \\
\text { de SP, MG e RJ (n=67) }\end{array}$} \\
\cline { 2 - 10 } & Média & Desvio padrão & Mín. & Máx. & Média & Desvio Padrão & Mín. & Máx. \\
\hline População estimada 2015(mil hab.) & 151 & 32 & 113 & 193 & 138 & 26 & 100 & 200 \\
\hline Distância da Capital (km) & 214 & 152 & 60 & 469 & 158 & 138 & 12 & 590 \\
\hline PIB per capita 2012 (R\$ mil) & 33 & 14 & 16 & 62 & 25 & 16 & 7 & 98 \\
\hline Orçamento per capita 2015 (R\$ mil) & 24 & 10 & 15 & 43 & 21 & 7 & 12 & 43 \\
\hline Área (km2) & 881 & 355 & 291 & 1.338 & 643 & 715 & 15 & 3.242 \\
\hline Idade de fundação em 2016 (anos) & 173 & 81 & 95 & 359 & 202 & 330 & 23 & 391 \\
\hline
\end{tabular}

A análise de conteúdo foi iniciada pela leitura prévia e não estruturada dos 72 relatórios, como em Campos (2004), e desenvolveu-se um protocolo para coletar, codificar e classificar o grau de conteúdo informacional presente nos indicadores e providências. A extração nos ARF incluiu (i) os riscos fiscais divulgados, (ii) o valor dos riscos divulgados, e (iii) as providências para cada risco. Foram coletados 211 riscos e 42 providências sugeridas nos 72 relatórios.

Os indicadores e valores estimados de riscos e providências foram classificados em "similar" ou "não similar" em relação aos exemplos e recomendações da Secretaria do Tesouro Nacional e do Tribunal de Contas ao qual o município é jurisdicionado. Ainda, foi classificado se era similar ou não em relação ao apresentado no relatório do ano anterior daquele governo.

Como é natural esperar que certos indicadores se repitam ao longo do tempo, por se tratarem efetivamente de riscos de caráter continuado, os indicadores foram categorizados em: (i) riscos permanentes e (ii) riscos temporários, utilizando a definição de Kopits (2014). A análise da similaridade ao longo da série isolou e tratou apenas os riscos temporários, que seriam suscetíveis à variação de cenários no tempo, sendo esperado ajustes. A variação dos riscos considerados permanentes na série não foi analisada pois 
estes são eventos de ocorrência potencial constante como eventos da natureza (como eventos naturais) que podem estar expostos.

Para fins de análise agrupamos os casos em padrões de conteúdo informacional e comparamos os casos. Ao longo da análise de conteúdo, o conceito de baixo conteúdo informacional foi desenvolvido de forma indutiva. Os indicadores e providências informados pelas prefeituras foram classificados dessa forma quando se enquadravam nas seguintes regras: (i) são exatamente iguais aos exemplos dos manuais, sem que fossem acompanhados de um detalhamento, seja na própria tabela do relatório, ou em notas explicativas; (ii) os relatórios não possuem informação sobre como os riscos e providências foram mensurados; e (iii) os indicadores de risco e providências não variam no tempo, considerando tanto o texto quanto seus valores.

Essas características sugerem que os indicadores de riscos foram elaborados apenas para cumprimento de legislação e prazos, visto que as sugestões dos manuais são genéricas e requerem um detalhamento, como, por exemplo, utilizar o indicador 'demandas Judiciais', ou o indicador de risco'discrepância de projeções', mas sem informar a natureza da projeção, ou utilizar a providência'contingenciamento de despesas', sem indicar qual despesa seria contingenciada. Assim, as informações que foram enquadradas em pelo menos uma das características mencionadas, foram classificadas como sendo casos de 'baixo conteúdo informacional.'

Por fim, para analisar a atuação do controle externo, foram observados, por meio de análise de conteúdo, os seguintes pareceres prévios sobre prestação de contas emitidos pelos respectivos Tribunais de Contas, que eram os últimos disponíveis no período: Belo Horizonte (2015); Passos (2013); Itabira (2014); Poços de Caldas (2015); São Paulo (2014); Itu (2014); Araçatuba (2014); Catanduva (2014); Teresópolis e Resende - (2014 a 2016); Angra do Reis - (2014 e 2015).

\section{Fontes de legitimação do Anexo de Riscos Fiscais}

No campo organizacional, a Secretaria do Tesouro Nacional (STN) e os Tribunais de Contas (TC), ambos com poder de punir o descumprimento da LRF são fontes de legitimação. A STN pode impedir transferências voluntárias aos municípios e não aprovar pedidos de operações de crédito, e os TCs podem (i) multar os prefeitos; (ii) recomendar a reprovação das contas; (iii) negar a certidão de regularidade, impedindo o recebimento de operações de crédito. Assim, os modelos e exemplos presentes em seus manuais passam a ser um porto seguro para prefeituras que buscam reduzir o risco de não conformidade com a normativa desses órgãos.

A Tabela 2 apresenta as 6 fontes de legitimação para os casos selecionados. A STN é uma fonte similar a todos os casos, os TCM para seus jurisdicionados, as capitais São Paulo e Rio de Janeiro, e os TCE para os demais municípios. A STN publicou em 2004 o manual de elaboração do 'Anexo de Riscos Fiscais e Relatório de Gestão Fiscal', e a partir de 2008 o 'Manual Técnico de Demonstrativos Fiscais' - MDF. As 25 versões de manuais e cartilhas mencionam ao todo mais de 156 exemplos de riscos com 38 exemplos de providências (Tabela 2).

Tabela 2: Orientações normativas de STN e Tribunais de Contas dos estados analisados

\begin{tabular}{|c|c|c|c|c|c|c|}
\hline Origem do modelo & $\begin{array}{c}\text { Publica manual de } \\
\text { orientação com } \\
\text { modelo de ARF }\end{array}$ & $\begin{array}{c}\text { Versões de modelos } \\
\text { e manuais (N) }\end{array}$ & $\begin{array}{c}\text { Quantidade de Riscos } \\
\text { "sugeridos" }\end{array}$ & $\begin{array}{c}\text { Quantidade de } \\
\text { Providências } \\
\text { "sugeridas" }\end{array}$ & $\begin{array}{c}\text { Forma de } \\
\text { envio do } \\
\text { ARF }\end{array}$ & $\begin{array}{c}\text { Disponibiliza as } \\
\text { informações em } \\
\text { seu portal? }\end{array}$ \\
\hline STN & Sim & 25 & 156 & 38 & - & \\
\hline
\end{tabular}




\begin{tabular}{|c|c|c|c|c|c|c|}
\hline TCM-SP & Não & 0 & 0 & 0 & Papel & - \\
\hline TCM-RJ & Não & 0 & 0 & 0 & Papel & - \\
\hline TCE-SP & Sim & 7 & 25 & 4 & Papel & - \\
\hline TCE-RJ & Não & 0 & 0 & 0 & Papel & - \\
\hline TCE-MG & Sim & 3 & 30 & 0 & Eletrônica & Sim \\
\hline
\end{tabular}

Fonte: Elaborada pelos autores. Nota: TCE significa Tribunal de Contas do Estado; TCM significa Tribunal de Contas do Município; ARF significa Anexo de Riscos Fiscais

Apesar do histórico de divulgações de manuais de orientações, o Tribunal de Contas do Estado de São Paulo passou a tratar o tema 'riscos fiscais' de forma mais aprofundada apenas a partir de 2012. Em Minas Gerais, o Tribunal de Contas aborda atualmente o tema em seu sistema de coleta de dados (SICOM), porém o foco é em um layout para transmissão dos dados, e não exemplifica os riscos e providências. O Tribunal de Contas do Estado do Rio de Janeiro, assim como os Tribunais de Contas específicos das capitais (Rio de Janeiro e São Paulo) não emite manuais ou modelos.

Os modelos e exemplos nos manuais mencionados não têm força de lei. São apenas um tipo de orientação profissional, ao ser proposto por especialistas no tema. Os modelos na STN são elaborados por grupos técnicos com participação de diversos profissionais, inclusive do órgão regulador contábil (Conselho Federal de Contabilidade - CFC). Contudo, é difícil afirmar que o agente local consegue fazer a distinção de que tal modelo é apenas uma sugestão.

Pode ser excessivamente otimista a consideração que as equipes nas prefeituras segreguem as fontes de orientação para gestão de conformidade. Se a equipe na prefeitura toma o manual como compulsório, o efeito será similar à uma pressão coercitiva. Porém, se ela reconhece que se apenas tratam de exemplos, ainda assim pode optar por segui-los para reduzir o risco de não conformidade. Neste último caso, deveria ser visto como efeito de uma pressão normativa.

\section{PADRÕES DE CONTEÚDO INFORMACIONAL DO ARF}

Os resultados do levantamento dos riscos e providências das 12 prefeituras analisadas são apresentados na Tabela 3. Para fins de discussão, os casos foram agrupados e ordenados pelo conteúdo informacional dos indicadores e providências listados nos relatórios. A tabela não é exaustiva, de forma que há a possibilidade de serem observados outros padrões. A forma de classificação adotada permite agrupar os casos em 4 grupos, interpretados nesta seção de análise.

Na sequência são discutidos os: (i) riscos e providências informados (e não informados) pelos municípios; (ii) variação dos riscos e providências ao longo do período; (iii) padrões de conteúdo informacional; e (iv) Influência de modelos e coerção da STN e Tribunais de Contas.

Tabela 3: Riscos e providências (entre parênteses) identificados nos Anexos de Riscos

\begin{tabular}{|c|c|c|c|c|c|c|c|}
\hline \multirow[b]{2}{*}{ Municipios } & \multirow[b]{2}{*}{$\begin{array}{l}\text { Total de riscos e } \\
\text { de providências } \\
\text { (1) }\end{array}$} & \multirow[b]{2}{*}{$\begin{array}{l}\text { Sem conteúdo } \\
\text { informacional (\%) }\end{array}$} & \multirow[b]{2}{*}{$\begin{array}{l}\text { Similar } \\
\text { aos manuais } \\
\text { (2) (\%) }\end{array}$} & \multicolumn{3}{|c|}{ Variação ao longo do período (3) } & \multirow[b]{2}{*}{ Grupo } \\
\hline & & & & $\begin{array}{l}\text { Mudança } \\
\text { indicadores } \\
\text { e valores } \\
\text { (\%) }\end{array}$ & $\begin{array}{l}\text { Atualização apenas } \\
\text { dos valores } \\
(\%)\end{array}$ & $\begin{array}{l}\text { Repetição total } \\
\text { (\%) }\end{array}$ & \\
\hline Catanduva/SP & $0(0)$ & $-(-)$ & $-(-)$ & $-(-)$ & $-(-)$ & $-(-)$ & \multirow{5}{*}{ A } \\
\hline Itu/SP & $15(6)$ & $100(100)$ & $100(0)$ & $0(20)$ & $20(20)$ & $80(60)$ & \\
\hline Teresópolis/RJ & 42 (14) & $100(100)$ & $98(64)$ & $29(0)$ & $14(64)$ & $57(36)$ & \\
\hline São Paulo/SP & $35(0)$ & $100(-)$ & $0(-)$ & $45(-)$ & $0(-)$ & $55(-)$ & \\
\hline Passos/MG & $206(50)$ & $81(98)$ & $84(0)$ & $15(60)$ & $6(27)$ & $79(13)$ & \\
\hline
\end{tabular}




\begin{tabular}{|c|c|c|c|c|c|c|c|}
\hline Araçatuba/SP & $24(5)$ & $75(100)$ & $13(0)$ & $0(20)$ & $100(60)$ & $0(20)$ \\
\hline $\begin{array}{c}\text { Poços de Caldas/ } \\
\text { MG }\end{array}$ & $25(20)$ & $60(100)$ & $4(0)$ & $33(25)$ & $40(69)$ & $27(6)$ \\
\hline Angra dos Reis/RJ & $18(17)$ & $50(100)$ & $33(36)$ & $29(39)$ & $57(46)$ & $14(15)$ \\
\hline Rio de Janeiro/RJ & $426(6)$ & $6(100)$ & $7(0)$ & $12(0)$ & $64(100)$ & $24(0)$ & B \\
\hline Resende/RJ & $25(18)$ & $4(100)$ & $20(61)$ & $20(7)$ & $80(93)$ & $0(0)$ \\
\hline $\begin{array}{c}\text { Belo Horizonte/ } \\
\text { MG }\end{array}$ & $19(8)$ & $0(100)$ & $95(0)$ & $6(0)$ & $94(100)$ & $0(0)$ \\
\hline Itabira/MG & $13(13)$ & $0(100)$ & $0(0)$ & $28,5(20)$ & $43(40)$ & $28,5(40)$ \\
\hline
\end{tabular}

Notas: A tabela toda (exceto a primeira coluna) mostra números percentuais de indicadores de riscos e as providências (sempre entre parênteses) em relação ao total nos relatórios de 2011 a 2016. Em toda tabela, a marcação (-) indica casos em que o total de indicadores ou providências no período é zero para a classe analisada. Notas específicas: (1) Nesta coluna os números estão em valores absolutos, e indicam as quantidades de riscos e entre parênteses, de providências. (2) Indicadores e providências iguais ou similares aos manuais da STN e TC. (3) Foram considerados apenas os riscos temporários, segundo a classificação de Kopits (2014).

\section{Riscos e providências informados (e não informados) pelos municípios}

Como apresentado na Tabela 3, de uma forma geral, a divulgação do ARF das prefeituras apresenta baixo conteúdo informacional. Como casos extremos, 9 relatórios (de 72) continham apenas conceitos de riscos, ou ainda mencionavam "não há previsão de riscos". Dentre as prefeituras, 4 não apresentaram nenhuma informação em notas explicativas durante todo o período. Ainda, quando essas eram apresentadas, tratavam apenas de definições, sem detalhar os riscos e providências, como suas memórias de cálculo, apesar de obrigatório pela LRF (art. $4^{\circ}$ \$2).

Outro fator a ser observado é a em relação ao conteúdo informacional dos indicadores. Entre as prefeituras selecionadas, Resende e Itabira são exemplos positivos, assim como as capitais Belo Horizonte e Rio de Janeiro. Porém, Araçatuba, Passos, Teresópolis e a capital de São Paulo, possuem mais de 70\% de seus indicadores sem conteúdo informacional. Ainda, estas 4 prefeituras mantiveram o mesmo conjunto de informações por diversos períodos.

Os indicadores de providências apresentam as mesmas características de falta de detalhamento e clareza dos indicadores de riscos informados. As providências deveriam ser ações exequíveis e que determinem um claro e direto comando a ser executado na ocorrência do evento de risco.

Diversos relatórios apresentaram inconsistências, o que pode indicar que as informações dos mesmos não são utilizadas. Podem-se citar alguns casos emblemáticos. Em um dos relatórios, o somatório nos valores dos riscos e providências não totalizavam os itens analíticos listados no relatório. Em outro caso, a soma da anulação da reserva de contingência superava a reserva de contingência do orçamento, tornando a providência sem efetividade real. Tais falhas podem ser simples erros, ou mesmo gerenciamento deliberado dos riscos e as providências propostas, visto que as providências não suportariam os riscos levantados.

A baixa atuação do controle externo foi observada na análise do último parecer prévio sobre a prestação de contas dos municípios analisados. Apenas nos pareceres emitidos para os municípios de São Paulo em 2016 e Itu em 2014 foram encontrados questionamentos sobre o conteúdo dos relatórios do Anexo de Riscos Riscais. Apenas em 2 pareceres foram encontrados questionamentos dos Tribunais em relação ao Anexo de Riscos Fiscais. Para o Município de São Paulo em 2016 o Tribunal observou que os riscos deveriam ser quantificados. Para Itu, o Tribunal Identificou que uma operação de compensação previdenciária realizada pela Prefeitura deveria ter sido evidenciada como um risco no Anexo. Além disso, a baixa variação na situação dos indicadores de riscos e providências verificada ao longo dos 6 anos seria outra evidência da baixa atuação dos Tribunais de Contas em relação ao seu acompanhamento dos ARF. 
Os resultados das providências apuradas nos ARF (Tabela 4) demonstram que em geral essas têm sido informadas de forma genérica, praticamente sem conteúdo informacional. Encontramos casos em que os valores das providências apontadas são insuficientes para enfrentar os riscos divulgados.

Entre as providências propostas estão sugestões genéricas, como anular dotações do orçamento sem indicação de sua natureza ou origem da despesa a ser afetada. Foram encontrados casos em que o campo destinado às providências foi utilizado apenas para repetir o mesmo texto dos riscos fiscais. Além disto, praticamente todas as providências apresentadas estão sem conteúdo informacional (99\% do total no período), ou seja, são informadas apenas para constar no relatório.

Tabela 4: Tipos de providências sugeridas para os 9 municípios (exceto as capitais)

\begin{tabular}{|c|c|c|c|c|c|c|c|}
\hline Providências & 2011 & 2012 & 2013 & 2014 & 2015 & 2016 & Total \\
\hline Limitação genérica de despesas (2) & 7 & 10 & 12 & 13 & 12 & 7 & 61 \\
\hline Uso da reserva de contingência (2) & 7 & 7 & 8 & 7 & 4 & 7 & 40 \\
\hline Providência genérica (1) & 6 & 3 & - & 3 & 3 & 3 & 21 \\
\hline Reserva de contingência ou limitação de despesas (2) & - & 1 & 2 & 4 & 3 & 3 & 13 \\
\hline Redução de investimentos (2) & 1 & 1 & 1 & 1 & 1 & 1 & 6 \\
\hline Providência já estimada na Lei Orçamentária & - & - & - & - & 2 & - & 2 \\
\hline Créditos adicionais não especificados & - & - & - & - & 1 & - & 1 \\
\hline Reajustes tarifários & - & - & - & 1 & - & - & 1 \\
\hline Risco repetido como providência & - & - & - & - & - & 1 \\
\hline Total de providências & 51 & 52 & 44 & 56 & 55 & 48 & 146 \\
\hline
\end{tabular}

Fonte: elaborada pelos autores. Notas: (1) Uma "providência genérica" é entendida como aquela que não apresenta uma ação concreta para sua execução, como nos exemplos "Precatórios Judiciais", "Demandas Naturais" ou "Inadimplência Tributária", não existe um verbo que concretize a ação, nem os detalhes; (2) Estas providências são tipicamente anulações genéricas de dotações do orçamento, pois não indicam a natureza da conta que será afetada. Um exemplo de detalhamento (não observado nos relatórios) seria "Anulação de dotação para reforma da Unidade Básica de Saúde".

Nem todo risco mencionado pelas prefeituras obrigatoriamente precisa apresentar uma providência associada, portanto era esperado que o número de providências fosse menor que o de riscos. Mas o que se observa é significativa ausência de providências que antecipem a real discussão dos procedimentos a adotar caso o evento ocorra, e transformem a forma de operação da prefeitura, as chamadas ações transformativas da literatura de resiliência financeira (Barbera et al, 2017).

\section{Variação dos risicos temporários e providências ao longo do período}

A variação dos indicadores de riscos temporários e de providências ao longo do período sugere baixo uso de tais informações (Tabela 3). Isso porque, se os indicadores são constantemente repetidos, a prefeitura pode simplesmente não estar atualizando as informações, ou estar informando corretamente caso este risco realmente esteja constante em probabilidade e impacto, o que é muito pouco provável.

Dentre os 368 indicadores de risco presentes nos relatórios, 235 se mantiveram inalterados ao longo do período (63,9\%). Desses, 173 (74\%) repetiram inclusive os valores ao longo do período. Ou seja, a mensuração ou revisão do valor do risco para aquele ano e contexto econômico não está sendo feita. A prefeitura de Passos que mantém um dos conjuntos de indicadores mais extenso chega a ter 79\% de seus indicadores sem qualquer variação no período analisado. Mesmo para os casos em que não há a repetição total da descrição do indicador e de seus valores, as prefeituras mantêm a descrição dos indicadores e apenas atualizam os valores.

Das 12 prefeituras analisadas, 4 delas repetiram de um relatório do ano anterior para o seguinte mais de $50 \%$ da descrição e dos valores dos indicadores. A duplicação de informações de exercícios anteriores 
pode indicar também o uso de algum software ou planilha eletrônica que importe automaticamente os dados de relatório do período anterior como ponto de partida para o relatório a ser elaborado. A repetição ou duplicação se agrava ao considerar que boa parte dos indicadores que não possuem conteúdo informacional estão sendo mantidos ao longo dos anos. Essa repetição pode indicar a baixa atenção que as equipes das prefeituras dão à necessidade de levantamento dos riscos inerentes ao município.

\section{Padrões de conteúdo informacional}

O baixo conteúdo informacional, caracterizado pela alta similaridade (não justificada) com manuais dos normatizadores, ausência de mensuração dos riscos, assim como a mera repetição da informação, evidencia uma adoção cerimonial do Anexo de Riscos Fiscais. A Tabela 3 apresentou os casos classificados em 4 grupos. Destaca-se que a tabela não é exaustiva, e outras classificações podem ser feitas.

Em todos os grupos $(A, B, C$ e $D)$ há baixo ou nenhum conteúdo informacional das providências. Isso pode indicar um claro descasamento entre o planejamento do município com gestão de riscos, visto que as providências deveriam indicar ações concretas do governo para o atendimento ao evento. Relatórios que tenham riscos previstos, porém sem providências, transferem a busca por soluções alternativas a eventos imprevistos para o momento em que o evento ocorreu, possivelmente gerando decisões subótimas, se comparadas com aquelas que teriam sido planejadas previamente. Sendo as providências um elemento essencial para a gestão de riscos, a falta ou limitação dessas sinaliza uma gestão de riscos inoperante.

Quanto aos indicadores de riscos fiscais, há variação entre os grupos analisados. Nos casos do grupo D as prefeituras entregam um relatório simples, com um conjunto de indicadores de menor similaridade com os manuais de STN e Tribunais de Contas (exceto Belo Horizonte). No caso de Belo Horizonte, por ser uma capital com desafios urbanos potencialmente similares à São Paulo e Rio de Janeiro, e mais recursos, o uso de poucos indicadores pode não ser uma virtude, se as fontes de riscos não tiverem sido definitivamente sanadas. Neste grupo, os riscos que foram elencados inicialmente, são preservados ao longo dos anos, mas, em geral os valores são atualizados (mesmo Itabira, que repete o valor de mais de um quarto dos seus indicadores). A marca desse grupo é o valor informacional dos indicadores, maior que todos os demais grupos. Nos grupos B e A, começa a surgir baixo conteúdo informacional também nos indicadores de riscos.

Os casos no grupo A, além do já mencionado baixo conteúdo informacional, sejam similares ou não aos exemplos dos manuais, têm indicadores e providências pouco atualizados. Um exemplo é a cidade de São Paulo, que tem emitido relatórios sem a mensuração dos riscos, com grande repetição das informações, o que já foi inclusive apontado pelo Tribunal de Contas. É um caso que permitiria concluir pela existência de falta de percepção de utilidade no relatório como instrumento de planejamento, dada a estrutura do município. Ainda, quando o grupo A é comparado em relação aos demais grupos, claramente têm a maior porcentagem de riscos repetidos (descrição e valores estimados) nos anos. O caso do município de Passos indica um sistema implantado além da capacidade da prefeitura gerenciá-lo, com muita similaridade com os manuais, podendo não representar as especificidades e necessidades locais, que apesar do extenso conjunto de riscos e providências, em grande parte não tem conteúdo e é apenas repetido nos anos.

O grupo B reúne casos que podem passar por um desgaste do sistema de riscos, ao serem observados os relatórios ao longo dos anos. Sobretudo Poços de Caldas (MG) e Angra dos Reis (RJ), mesmo 
escolhendo níveis diferentes de similaridade em relação aos exemplos dos manuais, grande parte dos riscos não têm conteúdo informacional, parte passou a ser apenas atualizada, e parte já é apenas repetida sem atualização. $\mathrm{O}$ caso de Araçatuba (SP) mostra um sistema que ainda não entrou na fase de mera repetição de valores.

A prefeitura do Rio de Janeiro é um caso à parte (grupo C). O caso mostra a complexidade do município do Rio de Janeiro, e como isso se reflete em indicadores com alta especificidade em muitos temas críticos de gestão urbana cobertos pelo sistema de riscos implantado. De tão numerosos, naturalmente a similaridade é baixa com a STN (dado que o Tribunal de Contas do Município não possui um modelo), simplesmente porque os exemplos nos manuais são poucos. Este foi o único caso analisado que segrega a evidenciação dos riscos por órgão municipal, e busca consolidar as informações no anexo. Porém em grande parte dos indicadores apenas são atualizados os seus valores, e limita-se a apresentar uma única providência associada, sem conteúdo informacional. O município do Rio de Janeiro já apresenta identificação dos riscos (risk identification e risk assessment), mas ainda não trabalha largamente com providências (risk response). Contudo, destaca-se o limitado número de providências se comparado com o número de indicadores de riscos.

Ao longo da análise o caso do Rio de Janeiro se diferenciou de todos os demais. Apesar de ter complexidade urbana e de gestão municipal de uma capital como São Paulo e Belo Horizonte, o conjunto de seus indicadores é claramente diferente dos seus dois pares. 0 município reuniu 426 riscos divulgados nos seus relatórios nos 6 anos analisados, com apenas 7\% de similaridade com os modelos normativos. Enquanto Belo Horizonte possui alta similaridade com a normativa do Tribunal de Contas do estado e STN e São Paulo baixo conteúdo infromacional em geral.

\section{Influência de modelos e coerção da STN e Tribunais de Contas}

Como parte do baixo conteúdo informacional observado, os indicadores de riscos e providências são apresentados de forma sintética, sem detalhes, muito similar aos manuais das fontes externas de legitimação STN e Tribunais de Contas. Estes riscos propostos de forma similar aos manuais são em geral réplicas dos exemplos apresentados pelo órgão de controle.

O uso de riscos e providências com similaridade aos dos manuais tem grande variação. Nos riscos, a similaridade varia de 0\% (São Paulo) a 100\% (Itabira), e para as providências, de 0\% (Passos) a 64\% (Teresópolis. O município de Passos é um caso emblemático, pelo número de providências mencionadas (50 para 206 riscos), assim como por nenhuma delas ser similar às exemplificadas pela STN (porém com $40 \%$ das providências apresentando repetição ao longo dos anos). Já Teresópolis (RJ) tem $98 \%$ dos riscos e 64\% das providências inspirados nos manuais da STN.

Outro caso interessante é ltú (SP) que, a partir de 2012, parece ter mantido um relatório apenas para fins de prestação de contas, com um único risco e uma providência, similares ao manual do Tribunal de Contas. Entre as capitais, Belo Horizonte teve $95 \%$ dos indicadores de riscos com similaridade aos modelos do órgãos externos.

\section{ANÁLISE E DISCUSSÃO}

Os resultados evidenciaram baixo conteúdo informacional para ao menos dois terços de todos indicadores de riscos analisados. Quanto às providências, nenhuma análise apontou existência de conteúdo informacional. Este cenário não se alterou durante a série analisada. Nesse contexto, considerando que 
o Poder Legislativo não questiona as informações que recebe anualmente em conjunto com a LDO, e que os Tribunais de Contas também não focam seus esforços de auditoria sobre a temática, a resposta natural das prefeituras municipais é manter tudo como está.

Tal cenário pode indicar que a estratégia de cumprimento da legislação adotada pelos governos seja 'ter um relatório publicado', confiando na baixa verificação do conteúdo do relatório pelos Tribunais de Contas, o que seria uma típica resposta de ocultação de não conformidade (resposta de 'avoidance' em Oliver, 1991, associada a uma estratégia de decoupling). Assim, a publicação do relatório, mesmo sem conteúdo informacional seria uma resposta estratégica ao Manual de Demonstrativos Fiscais da STN, que prevê penalidades: “Propor LDO que não contenha os riscos fiscais na forma da lei: perda do mandato do Prefeito Municipal" (STN, 2014: 666). Publicando o relatório, o governo evita ser enquadrado na condição de pendência do relatório, estando, portanto, fora do alcance da penalidade. Nestes casos se evidenciaria uma condição mais profunda de elaboração cerimonial do relatório.

Uma das estratégias de avoidance (ver Oliver, 1991) utilizadas pelos municípios foi o procedimento de repetição de riscos e valores, como uma saída de baixo custo para a adoção cerimonial do relatório. Isso ocorre através da aceitação simbólica da norma, evitando, assim perda de legitimidade da organização no campo (Meyer \& Rowan, 1977). Tal realidade também é uma clara indicação da existência de baixo escrutínio externo. A repetição de valores acontece mesmo em municípios jurisdicionados ao Tribunal de Contas do Estado de Minas Gerais, que poderia se valer de uma análise automatizada dos dados de riscos coletados pelo seu sistema informatizado, como tratado na seção de metodologia. Assim, parece que as diferenças de controle entre os Tribunais não afetam a propensão ao uso cerimonial dos relatórios observado nos municípios.

Outra estratégia sugere o isomorfismo normativo (DiMaggio \& Powell, 1983), visando redução de incerteza ou legitimação, quando os municípios apresentam indicadores de riscos e providências de forma sintética, sem detalhes, e com alto grau de similaridade em relação aos manuais das fontes externas de legitimação STN e Tribunais de Contas.

Ao analisar em detalhes as providências, conclui-se que em geral os municípios não estão preparados para utilizar essa gestão de riscos como uma ferramenta antecipatória. Os principais tipos de providências utilizadas pelas prefeituras analisadas são tipicamente de curto prazo fazendo ajustes nas despesas para busca do equilibro fiscal (como apresentado na Tabela 4). Nesse sentido, os municípios brasileiros estariam por um lado mais expostos em cenários de crises e tensões continuadas, o que é uma ameaça a sua resiliência financeira (Barbera et al., 2017); por outro lado, a prestação de serviços seria afetada por respostas de curto prazo.

A fonte de legitimidade do relatório é de natureza fiscal - seja STN ou Tribunais de Contas - e a responsabilidade por sua elaboração normalmente é da Secretaria da Fazenda. Sugerimos que, como o relatório de riscos fiscais no Brasil foi criado pela LRF e é vinculado ao ciclo orçamentário anual, este tenderia a ser associado aos mesmos mecanismos orçamentários já existentes. Isso traria dois efeitos. Primeiro, o relatório de riscos fiscais seria encarado como apenas 'mais um' instrumento orçamentário, e já tem sido aceito no Brasil que o planejamento é impreciso, e com baixa credibilidade (Rezende \& Cunha, 2013). Em outros modelos como o do Reino Unido, o controle dos riscos é do tipo permanente, continuamente atualizado, e não apenas informado anualmente .

A ancoragem no planejamento orçamentário traz riscos fiscais que podem afetar as contas públicas em um curtíssimo espaço de tempo. Contudo, caso houvesse mecanismos de monitoramento contínuo desses eventos prováveis (riscos), a probabilidade de antecipação de choques e capacidade de uma rápida 
ação rápida seria maior (como em Barbera et al., 2017). Dessa maneira, sugere-se que o monitoramento dos riscos é tão importante quanto sua identificação elencada no planejamento inicial. Uma solução seria prever de forma objetiva que os riscos devem ser formalmente apresentados nas audiências públicas quadrimestrais de avaliação das metas da LDO - gerando força para o monitoramento contínuo dos riscos.

$\mathrm{O}$ segundo efeito relaciona-se à qual departamento ou setor assume a gestão de riscos. $\mathrm{O}$ fato do anexo de riscos fiscais no Brasil ser vinculado ao ciclo orçamentário, induz que o ARF seja elaborado pela Secretaria da Fazenda. E essa Secretaria pode acabar centralizando a gestão de riscos fiscais sem condições de operá-lo, apesar da recomendação dos normatizadores para que seja assumida pelo Controle Interno. Este órgão centralizador da gestão de risco, levantaria e agregaria todos riscos operacionais não financeiros das diversas secretarias, incluindo as providências a serem tomadas, caso os riscos ocorressem.

Essa centralização gera o desafio de os riscos não financeiros, seus impactos financeiros e suas providências financeiras e não financeiras, não serem plenamente captados no sistema. É uma questão de organização do sistema de gestão de riscos, que pode ser mais centralizado ou mais descentralizado entre as diversas áreas finalísticas, o que poderia facilitar ou inviabilizar o conteúdo informacional de indicadores e providências.

Uma maior cooperação entre as áreas finalística e financeira/orçamentária para operar o sistema de gestão de riscos global do município poderia favorecer o conteúdo informacional e uso do sistema. Isso aconteceria pois a gestão de riscos fiscais passaria efetivamente a considerar no orçamento os impactos tanto das variações operacionais na oferta de serviços, quanto o impacto de variações ambientais na demanda por serviços. Além disso, passaria a desenhar respostas (providências) financeiras e apoiar o desenho de soluções não financeiras para assimilar os efeitos dos eventos de risco.

Retomando a questão de quem deve operar o sistema, pelo entendimento divulgado por normatizadores (vide norma contábil "NBCT 16.8-Controle Interno") essa responsabilidade seria do "sistema de controle interno" das Prefeituras Municipais. O mesmo vem sendo discutido pela literatura, como Freitas (2016). Contudo, a criação de órgãos de controle interno também têm sido uma resposta cerimonial no Brasil (Lino et al., 2019). Naturalmente, nestes casos a gestão de riscos alocada em um órgão que tem atuação cerimonial, acabaria sendo por consequência cerimonial e sem função. Apesar da discussão do operador do sistema de gestão de riscos, a questão central é, independentemente do departamento responsável por conduzir ativamente a gestão de riscos, se este operar de forma isolada em relação às áreas finalísticas, é pouco provável que esta consiga captar a complexidade da gestão municipal e conectá-la ao orçamento anual.

\section{CONSIDERAÇÕES FINAIS E IMPLICAÇÕES}

Os relatórios 'Anexos de Riscos Fiscais' dos 12 municípios analisados no período de 2011 a 2016 mostram evidências de uma possível adoção superficial das práticas de gestão de risco em governos locais. As evidências são de três tipos. Primeiro, o uso de indicadores de riscos sem providências associadas; segundo, indicadores e providências que não são ajustados aos contextos nos diversos períodos; e terceiro, a similaridade com modelos propostos nos manuais dos órgãos de controle e autoridade fiscal, sem que haja um detalhamento das informações.

As informações evidenciadas nos relatórios não representam os reais riscos que as contas públicas nestes municípios possuem, comprometendo accountability e sustentabilidade fiscal. Existem boas chances de grande parte das prefeituras analisadas estar emitindo relatórios apenas para atender a legislação, ocorrendo uma divulgação cerimonial. Uma outra explicação seria um governo que tenha 
uma gestão de riscos fiscais operante, propositadamente deixar seu relatório desatualizado e com baixo conteúdo, reduzindo a transparência e o debate no legislativo, mas não temos evidências sobre essa suposição, o que nos leva a concluir pela primeira explicação.

Concluímos que o uso cerimonial ou chamado 'isomorfismo de superfície' (Zucker, 1987), como forma de decoupling que legitima o município perante o Tribunal de Contas, só é possível pela superficialidade da auditoria do Tribunal e do acompanhamento da Câmara Municipal, incluindo suas Comissões de Orçamento e Finanças. A baixa atenção do controle externo abre espaço para tal superficialidade. A forma mais simples e com chances de ter o relatório superficial aceito é sendo similar aos exemplos dados pelo próprio normatizador. Contudo, nossa análise apontou para um segundo efeito que afetaria a geração do ARF, a vinculação à dinâmica do ciclo orçamentário anual, incluindo as funções e áreas que são os operadores do orçamento.

Este uso cerimonial vai na contramão da solicitação de tendências internacionais de gestão fiscal, como proposto pelo Fundo Monetário Internacional (Ramkumar \& Shapiro, 2014). Ainda, é uma evidência de fraco planejamento orçamentário para antecipação de choques e providências, e, assim, de baixa resiliência financeira (Barbera et al., 2017). Além do baixo conteúdo informacional identificado, outros desafios limitam o modelo brasileiro de gestão de riscos orçamentários. O modelo atual não compara períodos e não faz projeções futuras que englobem diversos exercícios seguintes (Brixi \& Schick, 2002). Ou seja, o horizonte temporal não capta riscos de longo prazo (Rezende, Cunha \& Bevilacqua, 2010).

Da análise, surgem duas implicações. Primeiro, mostramos que a simples publicação de relatórios pode não significar um sistema operante. Com isso deixamos o alerta para que agências internacionais considerem que a simples existência de regulação descreve apenas parcialmente o avanço institucional de um país. Ainda, alertamos Tribunais de Contas e Secretaria do Tesouro Nacional do cuidado com auditorias superficiais, e publicação de rankings e índices que não captem a prática e processos, e que não analisem o conteúdo informacional dos diversos relatórios emitidos por governos. Na realidade, tais rankings superficiais apenas reforçam a prática cerimonial, pois governos terão incentivos de compliance e legitimação, para estarem nos rankings e índices apenas publicando um relatório cerimonial.

A segunda implicação diz respeito à forma como os novos mecanismos de gestão são conectados ao ciclo orçamentário vigente. Na análise emergiu a proposição de que a vinculação de práticas ao ciclo orçamentário condiciona a dinâmica de funcionamento das novas práticas ao modus operandi orçamentário daquele município. Se confirmamos essa proposição, a vinculação ao ciclo orçamentário e seus efeitos deveriam ser levados em consideração em estudos no tema e pelos normatizadores no desenho de suas estratégias. Deixamos aqui como sugestão de estudos futuros analisar diversos modelos de organização, e verificar o fluxo da informação de riscos e os demais gargalos na operação do sistema.

A principal limitação do presente estudo está associada à análise dos riscos em relatórios publicados, que apesar de permitir uma compreensão do fenômeno observado, limita-se a informações divulgadas publicamente, não considerando informações de riscos eventualmente omitidas pelos governos. Assim, sugere-se que pesquisas futuras analisem o controle de riscos fiscais através de estudos de caso, de forma a complementar o entendimento do cenário levantado. 
Almeida-Santos, P. S. (2015). Explorando a probabilidade da divulgação de passivos contingentes pelos governos locais brasileiros. Espacios Públicos, 18(42), 7-32.

Aquino, A.C.B. de, \& Cardoso, R. L. (2017). Financial Resilience in Brazilian Municipalities. In I. Steccolini, M. Jones, \& I. Saliterer (Eds.), Governmental Financial Resilience. Emerald Publishing Limited, 53-71. Doi: https://www.emeraldinsight.com/doi/abs/10.1108/S2053-769720170000027004.

Ashworth, R., Boyne, G., \& Delbridge, R. (2007). Escape from the Iron Cage? Organizational Change and Isomorphic Pressures in the Public Sector. Journal of Public Administration Research and Theory, 19(1), 165-187. Doi: https://doi.org/10.1093/jopart/mum038.

Barbera, C., Jones, M., Korac, S., Saliterer, I., \& Steccolini, I. (2017). Governmental financial resilience under austerity in Austria, England and Italy: How do local governments cope with financial shocks? Public Administration, 95(3), 670-697. Doi: https://doi.org/10.1111/padm.12350.

Brixi, H. P., \& Schick, A. (2002). Government at Risk: Contingent Liabilities and Fiscal Risk. New York: The World Bank.

Campos, C. J.G. (2004). Método de análise de conteúdo: ferramenta para a análise de dados qualitativos no campo da saúde. Revista Brasileira de Enfermagem, 57(5), 611-614. Doi: http://dx.doi.org/10.1590/ S0034-71672004000500019.

Cebotari, A., Davis, J. M., Lusinyan, L., Mati, A., Mauro, P., Pettrie, M., \&Velloso, R. (2008). Fiscal Risks: Sources, Disclosure, and Management. Washington: IMF.

Clements, B., Medas, P., Alves, M., Bornhorst, F., Gonguet, F., Irwin, T. \& Rossi, J. L. (2017). Brasil: Avaliação da Transparência Fiscal. In: IMF Country Report No. 17/104. Washington: IMF.

DiMaggio, P. J., \& Powell, W. W. (1983). The iron cage revisited: Institutional isomorphism and collective rationality in organizational fields. American Sociological Review, 48(2), 147-160. Doi: 10.2307/2095101.

Ferrari, A. L. S., $\bigotimes \&$ Senhoras, E. M. (2013). Riscos fiscais e Lei de Responsabilidade Fiscal no Estado de Santa Catarina. Cadernos de Finanças Públicas, 13, 273-303.

FMI. (2007). Código de boas práticas para a transparência fiscal. Washington: IMF.

Freitas, C. A. S. (2016). Controles Internos e Gestão de Risco na Administração Pública. In: Braga, M. V.de A., Bliacheriene, A.C. \& Ribeiro, R. J. B. (eds). Controladoria no Setor Público. pp. 179-192. Belo Horizonte: Ed. Fórum.

Greenwood, R., Oliver, C., Sahlin, K., \& Suddaby, R. (2008). Introduction. In: R. Greenwood, C. Oliver, K. Sahlin, \& R. Suddaby (Eds.), The Sage Handbook of Organizational Institutionalism (pp. 1-46). London: Sage. Doi: http://dx.doi.org/10.4135/9781849200387.

Gustavson, M., \& Rothstein, B. (2013). Can Auditing Generate Trust? The Organization of Auditing and the Quality of Government. In Reuter, M., Wijkström, F.; Kristensson -Uggla, B.(Eds). Trust and Organizations. Confidence across Borders, p. 41-63, New York: Palgrave Macmillan, 2013. Doi: https://doi. org/10.1057/9781137368812_3.

Hameed, F. (2005). Fiscal transparency and economic outcomes. IMF Working Papers, WP/05/225. Doi: http://doi.org/10.1002/pbc.

Hardy, K. (2010). Managing Risk in Government: An Introduction to Enterprise Risk Management. Financial Management Series, 2(10), 1-53.

HM Treasury. (2004). The Orange Book Management of Risk: Principles and Concepts. London: HM Treasury. London: HM Treasury. 
Kopits, G. (2014). Coping with fiscal risk. OECD Journal on Budgeting, 14(1), 47-71. Doi: https://doi. org/10.1787/budget-14-5jxrgssdqnit.

Kumar, M. S., \& Ter-Minassian, T. (2007). Promoting Fiscal Discipline. International Monetary Fund.

Lino, A. F., \& Aquino, A. C. B. de. (2018). A diversidade dos Tribunais de Contas regionais na auditoria de governos. Revista Contabilidade \& Finanças, 29(76), 26-40. Doi: https://doi.org/10.1590/ 1808-057x201803640.

Lino, A. F., Carvalho, L. B. de, Aquino, A. C. B., \& Azevedo, R. R. de. (2019). A falta de trabalho institucional e mudanças organizacionais incompletas em municípios brasileiros. Revista de Administração Pública, 53(2), 375-391. Doi: http://dx.doi.org/10.1590/0034-761220170404.

Lopes, V. C., \& Costa, A. de J. B. (2017). Vulnerabilidade das finanças municipais às catástrofes naturais. In:V Conferência Sul-americana de Contabilidade Ambiental Valores Humanos e Consumo Sustentável. Brasília, IMF.

Meyer, J.W., \& Rowan, B. (1977). Institutionalized Organizations: Formal Structure as Myth and Ceremony. American Journal of Sociology, 83(2), 340.

Nascimento, E. R., \& Debus, I. (2001). Entendendo a Lei de Responsabilidade Fiscal (2a ed). Brasília: Secretaria do Tesouro Nacional.

Nunes, S. P. P., Marcelino, G. F., \& Silva, C. A. T. (2019). Os Tribunais de Contas na interpretação da Lei de Responsabilidade Fiscal. Revista de Contabilidade e Organizações, 13, e145151. https://doi.org/10.11606/ issn.1982-6486.rco.2019.145151

Oliver, C. (1991). Strategic Responses to Institutional Processes. Academy of Management Review, 16(1), 145-179. Doi: http://doi.org/10.2307/258610.

Patton, M. Q. (2015). Qualitative Research \& Evaluation Methods. Thousand Oaks, CA: SAGE Publications.

Ramkumar, V., \& Shapiro, I. (2014). Guia para transparência em Documentos Orçamentários do Governo: Porque eles são importantes e o que eles devem incluir? Washington: International Budget Partnership.

Rezende, F., Cunha, A., \& Bevilacqua, R. (2010). Informações de custos e qualidade do gasto público: lições da experiência internacional. Revista de Administracao Pública, 44(4), 959-992.

Rezende, F., \& Cunha, A. (2013). A reforma esquecida. Orçamento, gestão pública e desenvolvimento. Rio de Janeiro: Ed. FGV.

Scott, R. W. (2014). Institutions and Organizations. Ideas, Interests, and Identities (4th ed.). Thousand Oaks, CA: SAGE Publications.

Silva, A. C., Carvalho, L.O, \& Medeiros, O. L. (2009). Dívida Pública: A Experiência Brasileira. Brasília: Secretaria do Tesouro Nacional: Banco Mundial.

STN. (2013). Divergências conceituais entre as orientações contidas no Manual de Demonstrativos Fiscais -MDF e as práticas estabelecidas pelos tribunais de contas. Disponível em: $<$ https://stn.fazenda.gov.br/ documents/10180/205525/Respostas_Questionrio_TCs.pdf>. Acesso em abril/2019.

STN.(2014). Manual de Demonstrativos Fiscais (MDF). 6a ed. Brasília: Imprensa Oficial.

STN.(2017). Manual de Demonstrativos Fiscais (MDF). 8a ed. Brasília: Imprensa Nacional.

Ter-Minassian, T. (2010). Conferência: A Lei de Responsabilidade Fiscal do Brasil sob uma perspectiva internacional. Cadernos FGV Projetos. Rio de Janeiro/RJ. 
Woods, M. (2009). A contingency theory perspective on the risk management control system within Birmingham City Council. Management Accounting Research, 20(1), 69-81. Doi: https://doi.org/10.1016/j. mar.2008.10.003.

Zucker, L. G. (1987). Institutional Theories of Organization. Annual Review of Sociology, 13(1), 443-464.

i Atualmente o grupo chama-se CTCONF - Câmara Técnica de Normas Contábeis e de Demonstrativos Fiscais da Federação.

ii A lei determina que os riscos elencados sejam acompanhados de providências. Porém não existe necessariamente uma relação de 1 risco para 1 providência.

iii Relatório de Riscos de Three Rivers District Council:<www.threerivers.gov.uk/download?id=35896>

\section{Como referenciar}

Azevedo, R. R.; Aquino, A. C. B. de; Lino, A. F.; Cavelmoretti, G. (2019). A precariedade do conteúdo informacional dos anexos de riscos fiscais de municípios brasileiros. Advances in Scientific and Applied Accounting, 12(2), Maio / Ago. 